\title{
A Little Goes a Long Way: How the Adult Brain Is Shaped by Musical Training in Childhood
}

\author{
Erika Skoe $^{1,2}$ and Nina Kraus ${ }^{1,2,3,4,5}$ \\ ${ }^{1}$ Auditory Neuroscience Laboratory, ${ }^{2}$ Department of Communication Sciences, ${ }^{3}$ Institute for Neuroscience, ${ }^{4}$ Department of Neurobiology and Physiology, \\ and ${ }^{5}$ Department of Otolaryngology, Northwestern University, Evanston, Illinois 60208
}

Playing a musical instrument changes the anatomy and function of the brain. But do these changes persist after music training stops? We probed this question by measuring auditory brainstem responses in a cohort of healthy young human adults with varying amounts of past musical training. We show that adults who received formal music instruction as children have more robust brainstem responses to sound than peers who never participated in music lessons and that the magnitude of the response correlates with how recently training ceased. Our results suggest that neural changes accompanying musical training during childhood are retained in adulthood. These findings advance our understanding of long-term neuroplasticity and have general implications for the development of effective auditory training programs.

\section{Introduction}

Many children engage in group or private music instruction, yet few continue with formal music instruction beyond middle or high school (Steinel, 1990). For those who continue into college or beyond, the sensory, cognitive, and neural benefits of long-term musical training are clear (Schneider et al., 2002; Musacchia et al., 2007; Patel and Iversen, 2007; Parbery-Clark et al., 2009, 2012; Zendel and Alain, 2012). Yet, we have an incomplete understanding of how such training influences the adult brain when music lessons begin and end before adulthood. Furthermore, we know that music instruction affects the developing brain (Moreno and Besson, 2005; Norton et al., 2005; Fujioka et al., 2006; Lappe et al., 2008; Hyde et al., 2009; Moreno et al., 2009, 2011); however, we do not know whether music-related neuroplasticity is maintained or reversed after training has stopped. To address whether musical training during childhood leaves an enduring imprint on the adult brain, we tested 45 adults and grouped them into three age- and IQ-matched groups based on self-reported histories of music instruction: $0,1-5$, and 6-11 years (Table 1). Both musically trained groups began instrumental practice around age 9 years, a common age for in-school music instruction to begin (Steinel, 1990) that also falls within the sensitive period for music skill development (Trainor, 2005; Penhune, 2011).

We evaluated whether the adult brain is sensitive to past musical training by recording auditory brainstem activity. We predicted that

\footnotetext{
Received April 19, 2012; revised June 4, 2012; accepted June 11, 2012.

Author contributions: E.S. and N.K. designed research; E.S. performed research; E.S. analyzed data; E.S. and N.K. wrote the paper.

This work was supported by Grants NSF-SBE0842376, NSF-BCS0921275, and the Knowles Hearing Center at Northwestern University. We thank Emily Spitzer, Trent Nicol, Jessica Slater, Adam Tierney, and Dana Strait for their input on the manuscript and experimental design.

The authors declare no financial conflicts of interest.

Correspondence should be addressed to Dr. Nina Kraus, Northwestern University, 2240 Campus Drive, Evanston, IL 60208.E-mail: nkraus@northwestern.edu.

DOI:10.1523/JNEUROSCI.1949-12.2012

Copyright $\odot 2012$ the authors $\quad 0270-6474 / 12 / 3211507-04 \$ 15.00 / 0$
}

musical training during childhood leads to more robust neural processing of sound later in life. Our predictions were based on evidence that auditory brainstem responses (ABRs) to complex sounds are sensitive to the lifelong musical experience (Kraus and Chandrasekaran, 2010), language you speak (Krishnan et al., 2005; Krishnan and Gandour, 2009), the instrument you play (Strait et al., 2012), early and extensive bilingual experience (Krizman et al., 2012), and short-term auditory training (Song et al., 2008, 2012; Carcagno and Plack, 2011; Chandrasekaran et al., 2012).

\section{Materials and Methods}

Subjects. Forty-five healthy adults participated in this study (age range: $18-31$ years). Informed consent was obtained in accordance with Northwestern University's Institutional Review Board. Subjects were divided into three groups of 15 based on self report of formal instrumental music instruction: $0,1-5$, and $6-11$ years (Tables 1,2 ). The ratio of males to females was similar across groups: $9 / 6,9 / 6,10 / 5$, respectively. Audiometric function, as assessed by air-conduction thresholds, was within normal limits ( $<20 \mathrm{~dB}$ normal hearing level for octave frequencies from 0.125 to $4 \mathrm{kHz})$, and equivalent among the groups $(p>0.5)$. The groups did not differ in age $\left(F_{(2,42)}=1.72, p=0.19\right)$ or IQ, as measured by the Wechsler Abbreviated Scale of Intelligence [two-scale IQ: $F_{(2,42)}=1.46, p=0.24$; (English) Vocabulary subtest: $F_{(2,42)}=0.74, p=0.47$, Matrix Reasoning subtest: $F_{(2,42)}=1.94, p=0.16$; Table 1]. Many of the subjects reported having some exposure to a second language, but the amount of experience did not differ among the groups $\left(F_{(2,42)}=1.30, p=0.28\right)$. Only two of the subjects indicated having early exposure to a second language $(<3$ years old) and being fluent in that language.

Electrophysiological recordings. ABRs were recorded to eight triangle waves ranging in fundamental frequency $\left(\mathrm{F}_{0}\right): 262,294,330,350,370$, 393,416 , and $440 \mathrm{~Hz}$. Each $333 \mathrm{~ms}$ stimulus was presented binaurally 300 times in a pseudorandom interleaved design at $70 \mathrm{~dB}$ SPL via ER-3A insert earphones (Etymotic Laboratories) with an interstimulus interval of $38.43 \mathrm{~ms}$. Subjects sat in a reclining chair in a sound-treated and electrically shielded booth.

ABRs were recorded with an analog-to-digital rate of $20 \mathrm{kHz}$ using a PC-based hardware/software system (SynAmps ${ }^{2}$ amplifier, Neuroscan Acquire 4.3; Compumedics). Three $\mathrm{Ag}-\mathrm{AgCl}$ electrodes were placed on 
Table 1. Group characteristics

\begin{tabular}{lllllll}
\hline Group & Age (in years) & IQ (standard score) & Starting age (in years) & Stopping age ${ }^{*}$ (in years) & ${\text { Total }{ }^{*} \text { (in years) }}^{\text {Years since music lessons }}{ }^{*}$ \\
\hline 0 years & $21.67(3.87)$ & $121.47(9.03)$ & & & & \\
$1-5$ years & $20.20(1.47)$ & $125.73(8.55)$ & $9.73(2.09)$ & $13.00(2.07)$ & $3.26(1.16)$ & $7.20(2.73)$ \\
$6-11$ years & $20.53(1.06)$ & $127.07(2.16)$ & $8.53(2.10)$ & $17.20(2.81)$ & $8.67(1.88)$ & $3.33(2.92)$ \\
\hline
\end{tabular}

Subjects were divided into three groups based on the number of years they played a musical instrument. The mean (SD) age and IQ are reported, in addition to the age at which music lessons started and stopped, the duration of music lessons, and how many years ago music practice ceased. ${ }^{*} p<0.01$.

Table 2. Subjects' musical history

\begin{tabular}{|c|c|c|c|c|}
\hline Group & Years of training & Starting age (years) & Years since & Instrument \\
\hline \multirow{15}{*}{$1-5$ years } & 1 & 13 & 8 & Saxophone \\
\hline & 2 & 10 & 10 & Saxophone \\
\hline & 2 & 10 & 7 & Piano \\
\hline & 2 & 12 & 7 & Cello \\
\hline & 3 & 7 & 8 & Piano \\
\hline & 3 & 7 & 11 & Piano \\
\hline & 3 & 10 & 8 & Piano \\
\hline & 3 & 11 & 6 & Clarinet \\
\hline & 4 & 6 & 13 & Piano \\
\hline & 4 & 8 & 6 & Piano \\
\hline & 4 & 8 & 8 & Piano \\
\hline & 4 & 11 & 4 & Viola \\
\hline & 4 & 12 & 3 & Piano \\
\hline & 5 & 10 & 5 & Cello \\
\hline & 5 & 11 & 4 & Clarinet \\
\hline \multirow[t]{15}{*}{$6-11$ years } & 6 & 6 & 9 & Piano, viola \\
\hline & 6 & 8 & 5 & Piano, guitar \\
\hline & 7 & 6 & 7 & Piano \\
\hline & 7 & 6 & 8 & Piano \\
\hline & 7 & 11 & 4 & Harp \\
\hline & 7 & 13 & 0 & Drums, guitar, voice \\
\hline & 8 & 10 & 1 & Trumpet \\
\hline & 9 & 10 & 2 & Flute \\
\hline & 10 & 8 & 2 & Cello \\
\hline & 10 & 8 & 3 & Piano, voice \\
\hline & 10 & 8 & 1 & Piano, guitar \\
\hline & 10 & 11 & 0 & Saxophone, voice \\
\hline & 11 & 7 & 4 & Piano, clarinet, saxophone \\
\hline & 11 & 7 & 4 & Piano, saxophone \\
\hline & 11 & 9 & 0 & Saxophone \\
\hline
\end{tabular}

For each of the musically-trained subjects, the number of years of musical training, the age at which training started, the number of years since training occurred, and the instrument(s) are reported. In cases where multiple instruments are reported, instruments are listed in order of acquisition.

the scalp in a vertical montage with the active electrode at $\mathrm{Cz}$, the reference electrode on the right earlobe, and the ground electrode at $\mathrm{FPz}$. Contact impedance was $<5 \mathrm{kOhms}$. Recordings were made with an online filter of $0.5-3000 \mathrm{~Hz}$ and processed off-line by filtering from 30 to $2000 \mathrm{~Hz}(12 \mathrm{~dB} /$ octave) and epoching over a $360 \mathrm{~ms}$ window that included $20 \mathrm{~ms}$ of prestimulus activity. After baseline correcting to the mean voltage of the prestimulus period, trials with activity exceeding $\pm 35 \mu \mathrm{V}$ were excluded and the remaining trials were averaged. Recording procedures followed previously published guidelines (Skoe and Kraus, 2010).

Data analysis. For each stimulus, we obtained a signal-to-noise ratio (SNR) measurement for the phase-locked, frequency-following response (Moushegian et al., 1973) of the ABR (50-250 ms). The SNR was calculated by applying a fast Fourier transform in MATLAB 2011b (Mathworks), finding the average response amplitude for the $\mathrm{F}_{0}(10 \mathrm{~Hz}$ bin surrounding the $\mathrm{F}_{0}$ peak), and then dividing this value by the average amplitude of the noise floor surrounding the $\mathrm{F}_{0}$ peak $(20 \mathrm{~Hz}$ bins on either side of the $\mathrm{F}_{0}$ range). For example, for the lowest tone $\left(\mathrm{F}_{0}=262\right.$ $\mathrm{Hz}$ ), the signal was defined as the average within $257-267 \mathrm{~Hz}$, and the noise was defined as the combined average within $237-257 \mathrm{~Hz}$ and $267-$ $287 \mathrm{~Hz}$. SNRs were entered into a 3 (group) $\times 8$ (stimulus) mixed-model multivariate ANOVA, with Bonferroni-corrected post hoc comparisons.
A

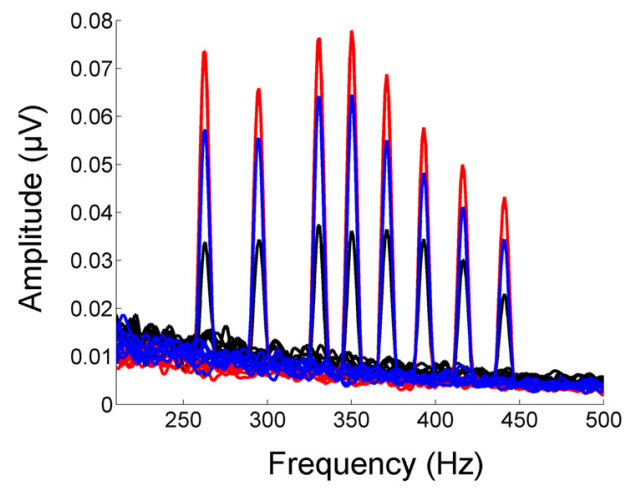

B

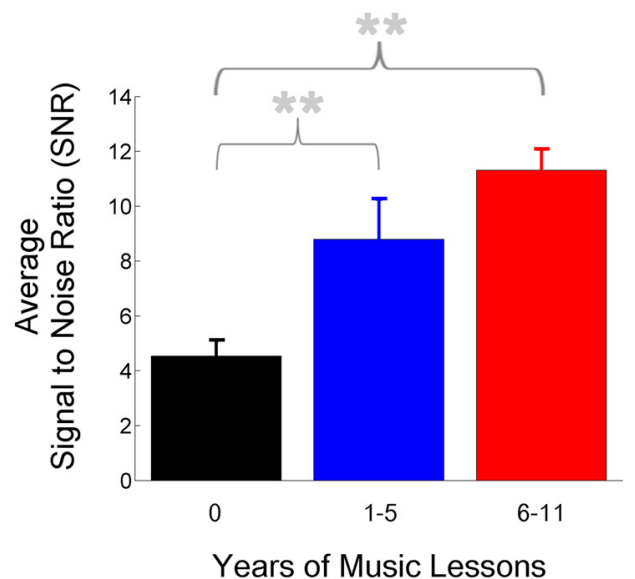

C

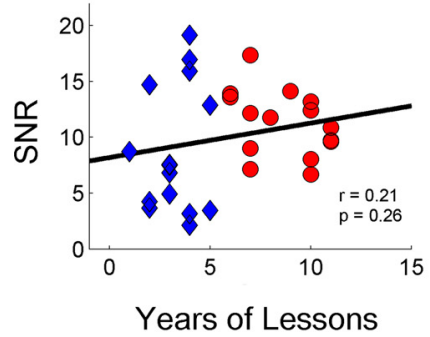

D

Figure 1. Music practice during childhood is associated with more robust neural responses to sound in adulthood. For adults with no past musical experience (black), the brainstem frequency-following response is diminished in amplitude (smaller SNRs) relative to adults who started playing a musical instrument around age 9 years and continued to play for either 1-5 (blue) or 6-11 (red) years. A, Frequency-following responses to eight sounds of varying frequency. $\boldsymbol{B}$, Average SNR across the eight sounds for each group (mean \pm 1 SEM). ${ }^{* *} p<0.01$. $C$, In the musically trained subjects, there is no correlation between the average SNR and years of music training $(r=0.21, p=0.26)$. D, Average SNR did correlate with how recently training occurred $(r=-0.41, p=0.02)$.

\section{Results}

We found that the brainstem response was more robust in adults with musical training compared with those with no past instrumental training (main effect of group: $F_{(2,42)}=11.65, p<0.0001$; no group $\times$ stimulus interaction: $F_{(14,294)}=1.22, p=0.28$; Fig. 
$1 A, B)$. Post hoc comparisons revealed that the untrained group had smaller brainstem responses (lower average SNR) than either of the trained groups (both $p<0.015$ ) but that the two musically trained groups did not differ from each other $(p>0.2)$. Within the musically trained groups, the average SNR of the brainstem response did not correlate with the amount of training $(r=0.21$, $p=0.26$; Fig. $1 C$ ), but it was inversely correlated with the recency of training $(r=-0.41, p=0.02$; Fig. $1 D)$.

\section{Discussion}

Our results suggest that a limited period of music lessons $(\sim 3$ years) during childhood fundamentally alters the nervous system such that neural changes persist in adulthood after auditory training has ceased ( $\sim 7$ years later). Our findings are consistent with reports that adult nonhuman animals receive residual behavioral benefits from brief auditory training that they received as juveniles (Sarro and Sanes, 2011), that regular physical activity early in life is associated with better cognitive function later in life in humans (Dik et al., 2003) and nonhumans (Gomes da Silva et al., 2012), and that past musical experience is predictive of enhanced cognitive performance in older adults (Hanna-Pladdy and MacKay, 2011). Although the present study did not investigate the enduring behavioral benefits of childhood music training, we draw from prior work linking enhanced auditory brainstem encoding with heightened auditory perception, executive function, and auditory-based communication skills (Parbery-Clark et al., 2009; Ruggles et al., 2011; Kraus et al., 2012; Krizman et al., 2012; Song et al., 2012) to suggest that musical training during development may produce long-lasting positive effects on the adult brain.

During development, negative alterations in the environment, such as noise or limited acoustic diversity, lead to longlasting neural despecializations, including reduced neural synchrony and decreased frequency selectivity (Zhang et al., 2002; Chang and Merzenich, 2003; Ruggles et al., 2011). In contrast, passive exposure to an enriched auditory environment can enhance neural activity in both young and old animals; however, in this case, neuroplasticity is labile and neural changes are reversed within a few weeks after animals are returned to standard laboratory conditions (Engineer et al., 2004; Percaccio et al., 2005). As suggested by our results, neural changes may be more long-lasting when enriched sensory experiences require active interaction with sound, such as occurs when playing a musical instrument. We also infer from our data that music-related neural changes are maintained after training stops but, as suggested by our correlational analyses, may fade to some degree over time. While our experimental design does not permit us to establish causality, and while inborn differences cannot be completely ruled out, the correlation between the recency of training and the size of the neural response implicates the role of past musical experience in shaping auditory brainstem function. To understand the permanency of the effects we observed, future work should evaluate an older population with previous musical training and/or follow individuals longitudinally after training has stopped.

Most neuroscientific research has focused on the relatively rare and exceptional music student who has continued an active music practice during college, or the rarer example of the professional musician who has spent a lifetime immersed in music. Here we focus on the more commonplace case of the music student who played an instrument for only a few years. By showing that music education during childhood, even in limited form, may influence the adult brain, our findings reinforce the propo- sition that music is an agent of positive experience-dependent plasticity (Kraus and Chandrasekaran, 2010). In addition to broadening our understanding of long-term neuroplasticity, our results have implications for education policy makers and the development of auditory training programs that can generate long-lasting positive outcomes.

\section{References}

Carcagno S, Plack CJ (2011) Subcortical plasticity following perceptual learning in a pitch discrimination task. J Assoc Res Otolaryngol 12:89-100.

Chandrasekaran B, Kraus N, Wong PC (2012) Human inferior colliculus activity relates to individual differences in spoken language learning. J Neurophysiol 107:1325-1336.

Chang EF, Merzenich MM (2003) Environmental noise retards auditory cortical development. Science 300:498-502.

Dik M, Deeg DJ, Visser M, Jonker C (2003) Early life physical activity and cognition at old age. J Clin Exp Neuropsychol 25:643-653.

Engineer ND, Percaccio CR, Pandya PK, Moucha R, Rathbun DL, Kilgard MP (2004) Environmental enrichment improves response strength, threshold, selectivity, and latency of auditory cortex neurons. J Neurophysiol 92:73-82.

Fujioka T, Ross B, Kakigi R, Pantev C, Trainor LJ (2006) One year of musical training affects development of auditory cortical-evoked fields in young children. Brain 129:2593-2608.

Gomes da Silva S, Unsain N, Mascó DH, Toscano-Silva M, de Amorim HA, Silva Araújo BH, Simões PS, Naffah-Mazzacoratti Mda G, Mortara RA, Scorza FA, Cavalheiro EA, Arida RM (2012) Early exercise promotes positive hippocampal plasticity and improves spatial memory in the adult life of rats. Hippocampus 22:347-358.

Hanna-Pladdy B, MacKay A (2011) The relation between instrumental musical activity and cognitive aging. Neuropsychology 25:378-386.

Hyde KL, Lerch J, Norton A, Forgeard M, Winner E, Evans AC, Schlaug G (2009) Musical training shapes structural brain development. J Neurosci 29:3019-3025.

Kraus N, Chandrasekaran B (2010) Music training for the development of auditory skills. Nat Rev Neurosci 11:599-605.

Kraus N, Strait DL, Parbery-Clark A (2012) Cognitive factors shape brain networks for auditory skills: spotlight on auditory working memory. Ann N Y Acad Sci 1252:100-107.

Krishnan A, Gandour JT (2009) The role of the auditory brainstem in processing linguistically-relevant pitch patterns. Brain Lang 110:135-148.

Krishnan A, Xu Y, Gandour J, Cariani P (2005) Encoding of pitch in the human brainstem is sensitive to language experience. Brain Res Cogn Brain Res 25:161-168.

Krizman J, Marian V, Shook A, Skoe E, Kraus N (2012) Subcortical encoding of sound is enhanced in bilinguals and relates to executive function advantages. Proc Natl Acad Sci U S A 109:7877-7881.

Lappe C, Herholz SC, Trainor LJ, Pantev C (2008) Cortical plasticity induced by short-term unimodal and multimodal musical training. J Neurosci 28:9632-9639.

Moreno S, Besson M (2005) Influence of musical training on pitch processing: event-related brain potential studies of adults and children. Ann N Y Acad Sci 1060:93-97.

Moreno S, Marques C, Santos A, Santos M, Castro SL, Besson M (2009) Musical training influences linguistic abilities in 8-year-old children: more evidence for brain plasticity. Cereb Cortex 19:712-723.

Moreno S, Bialystok E, Barac R, Schellenberg EG, Cepeda NJ, Chau T (2011) Short-term music training enhances verbal intelligence and executive function. Psychol Sci 22:1425-1433.

Moushegian G, Rupert AL, Stillman RD (1973) Laboratory note: scalprecorded early responses in man to frequencies in the speech range. Electroencephalogr Clin Neurophysiol 35:665-667.

Musacchia G, Sams M, Skoe E, Kraus N (2007) Musicians have enhanced subcortical auditory and audiovisual processing of speech and music. Proc Natl Acad Sci U S A 104:15894-15898.

Norton A, Winner E, Cronin K, Overy K, Lee DJ, Schlaug G (2005) Are there pre-existing neural, cognitive, or motoric markers for musical ability? Brain Cogn 59:124-134.

Parbery-Clark A, Skoe E, Kraus N (2009) Musical experience limits the degradative effects of background noise on the neural processing of sound. J Neurosci 29:14100-14107. 
Parbery-Clark A, Anderson S, Hittner E, Kraus N (2012) Musical experience offsets age-related delays in neural timing. Neurobiol Aging 33:1483.e1-1483.e4.

Patel AD, Iversen JR (2007) The linguistic benefits of musical abilities. Trends Cogn Sci 11:369-372.

Penhune VB (2011) Sensitive periods in human development: evidence from musical training. Cortex 47:1126-1137.

Percaccio CR, Engineer ND, Pruette AL, Pandya PK, Moucha R, Rathbun DL, Kilgard MP (2005) Environmental enrichment increases pairedpulse depression in rat auditory cortex. J Neurophysiol 94:3590-3600.

Ruggles D, Bharadwaj H, Shinn-Cunningham BG (2011) Normal hearing is not enough to guarantee robust encoding of suprathreshold features important in everyday communication. Proc Natl Acad Sci U S A 108:15516-15521.

Sarro EC, Sanes DH (2011) The cost and benefit of juvenile training on adult perceptual skill. J Neurosci 31:5383-5391.

Schneider P, Scherg M, Dosch HG, Specht HJ, Gutschalk A, Rupp A (2002) Morphology of Heschl's gyrus reflects enhanced activation in the auditory cortex of musicians. Nat Neurosci 5:688-694.
Skoe E, Kraus N (2010) Auditory brain stem response to complex sounds: a tutorial. Ear Hear 31:302-324.

Song JH, Skoe E, Wong PC, Kraus N (2008) Plasticity in the adult human auditory brainstem following short-term linguistic training. J Cogn Neurosci 20:1892-1902.

Song JH, Skoe E, Banai K, Kraus N (2012) Training to improve hearing speech in noise: biological mechanisms. Cereb Cortex 22:1180-1190.

Steinel DV (1990) Data on music education: a national review of statistics describing education in music and the other arts. Paper presented at Music Educators National Conference, Reston, Virginia.

Strait DL, Chan K, Ashley R, Kraus N (2012) Specialization among the specialized: auditory brainstem function is tuned in to timbre. Cortex 48:360-362.

Trainor LJ (2005) Are there critical periods for musical development? Dev Psychobiol 46:262-278.

Zendel BR, Alain C (2012) Musicians experience less age-related decline in central auditory processing. Psychol Aging 27:410-417.

Zhang LI, Bao S, Merzenich MM (2002) Disruption of primary auditory cortex by synchronous auditory inputs during a critical period. Proc Natl Acad Sci U S A 99:2309-2314. 